DOI: https://dx.doi.org/ 10.33289/IJRPC.10.2.2020.10(53)

\title{
DETERMINATION OF DEXIBUPROFEN AND TRAMADOL HCI BY SIMULTANEOUS UV SPECTROSCOPIC METHOD FROM BULK AND PHARMACEUTICAL DOSAGE FORM
}

\author{
Prachi Manish Pimple \\ SVKM's Dr. Bhanuben Nanavati College of Pharmacy, \\ V. M. Road, Vile Parle (W), Mumbai, India.
}

\begin{abstract}
Development and validation of accurate, easy, error-free, specific and sensitive simultaneous UV spectroscopic method for determination of Dexibuprofen and Tramadol $\mathrm{HCl}$ in bulk as well as in pharmaceutical dosage form containing a blend of these two drugs. Method A i.e. simultaneous equation method and method B Area under the curve are applied for the estimation of DEX and TRAM. Systematic analytical methods are employed in line using $264 \mathrm{~nm}$ and $271 \mathrm{~nm}$ i.e. $\lambda$ max of DEX and TRAM taking ethanol as a solvent. DEX and TRAM separately and in a blend of mixture comply with beer's law in concentration range $100-500 \mu \mathrm{g} / \mathrm{ml}$ and $20-120 \mu \mathrm{g} / \mathrm{ml}$. In addition, proposed study concludes that two drugs do not interact with each other in a solution. Both the drugs are found to be accurate and reproducible for the desired linearity concentration range. This method can be applied effectively in the regular simultaneous assessment of both the drugs from the dosage form free of interference due to excipients.
\end{abstract}

Kevwords: Exibuprofen, Tramadol, Simultaneous and UV method.

\section{INTRODUCTION}

Dexibuprofen is chemically (S)-Alpha-Methyl4- (2-Methyl Propyl) Benzene Acetic Acid. Dexibuprofen is a pharmacologically active enantiomer of racemic ibuprofen. Racemic ibuprofen is a non-steroidal substance with anti-inflammatory and analgesic effects. Its mechanism of action is due to the inhibition of prostaglandin synthesis ${ }^{1}$. Tramadol $\mathrm{Hcl}$ is chemically rac-(1R,2R)-2(dimethylaminomethyl)- 1-(3-methoxyphenyl)cyclohexanol it work through modulation of the GABAergic, noradrenergic and serotonergic systems, in addition to its mild agonism of the $\mu$-opioid receptor ${ }^{2}$.It is reported that the addition of Tramadol $\mathrm{HCl}$ to existing NSAID therapy provides effective pain relief in patients with osteoarthritis flare pain. Tablets containing $400 \mathrm{mg}$ of Dexibuprofen and $50 \mathrm{mg}$ of Tramadol $\mathrm{HCl}$ combination if taken twice in a day are effective novel dosage forms for osteoarthritis.

\section{MATERIALS}

Shashun pharma and Organosys pharma provided a gift sample of Dexibuprofen and Tramadol $\mathrm{HCl}$ respectively. Ethanol AR grade procured from Vivochem B.V.

\section{Equipment}

UV spectra of reference standard as well as sample solutions and absorbance of all the sample solutionswere recorded using a UV spectrophotometer system (Jasco V530). Mettler Toledo balances are used for weighing all samples.

\section{Procedure}

Selection of solvent and wavelength

Solubility of Dexibuprofen and Tramadol $\mathrm{HCl}$ was scanned invarious solvents like ethanol, methanol, and water. All drug solutions were examined for UV spectra. An ethanolic solution of both the drugs has shown maximum absorbance compared to other solvents. Two wavelengths i.e. $264 \mathrm{~nm}$ and $271 \mathrm{~nm}$ selected as $\lambda$ max of Dexibuprofen and Tramadol $\mathrm{HCl}$. 


\section{Drug solutions}

Accurately weighed $50 \mathrm{mg}$ of standard DEX and TRAM solubilized in $20 \mathrm{ml}$ ethanol and volume was made up to $50 \mathrm{ml}$ using ethanol as a solvent in $50 \mathrm{ml}$ volumetric flask. The drug solution was filtered through a $0.45 \mu$ filter.

\section{Preparation of calibration curve}

Aliquots of standard drug solutions were withdrawn i.e. 1-6ml for DEX and 0.2-1.2 $\mathrm{ml}$ for TRAM and volume was made up to $10 \mathrm{ml}$ using ethanol as solvent. Concentration versus absorbance was plotted and recorded to be linear for both the drugs as shown in Fig no 5 and 6 . The calibration curve was plotted at a concentration range from $100-500 \mu \mathrm{g} / \mathrm{ml}$ and 20- $120 \mu \mathrm{g} / \mathrm{ml}$ for Dexibuprofen and Tramadol $\mathrm{HCl}$ respectively. The correlation coefficient was found to be 0.9983 and 0.9982 respectively for Dexibuprofen and Tramadol as shown in fig 4 and 5.

\section{Precision}

Suitable statistical estimation done to confirm the reproducibility of the developed method. The amount of drugs were determined thrice in a day at an interval of 2 hours on three different days for inter and intraday study respectively.

\section{Limit of detection (LOD)}

Minimum concentration of drug solution under study which can be detectable but not measurable is LOD. It is recorded as $1 \mu \mathrm{g} / \mathrm{mL}$ and $0.5 \mu \mathrm{g} / \mathrm{mL}$ for DEX and TRAM respectively.

\section{Limit of quantification (LOQ)}

It is a minimum drug solution under study which can be detectable as well as measurable is LOQ. It is recorded as $10 \mu \mathrm{g} / \mathrm{mL}$ and $5 \mu \mathrm{g} / \mathrm{mL}$ for DEX and TRAM respectively.

\section{Percentage recovery studies}

Precision of the developed method was estimated in terms of percentage recovery studies. The Amount of drug added to the solvent and amount of drug recovered after taking absorbance of drug solution at their $\lambda \max$ were evaluated. The procedure was repeated for three times and the concentration of drug in solution was recorded as a percentage of the analyte.

\section{Spectroscopic simultaneous equation method (Method A)}

For computable estimation of both the drugs understudy based onUV spectra of each drug two wavelengths i.e. $\lambda$ max of each drug is selected. Two wavelengths i.e. $264 \mathrm{~nm} \lambda \max$ of Dexibuprofen and $271 \mathrm{~nm} \lambda \max$ of Tramadol $\mathrm{HCl}$ were fixed for the systematic analytical method development. Sets of the simultaneous equation were developed taking the absorptivity coefficient at selected wavelengths in an account. To estimate the amount of each drug in mixturetwo sets of the simultaneous equation were constructed.

The amount of each drug from the blend was computed using the following two sets of simultaneous equations

$$
\begin{gathered}
\text { CDEX = A2 } \times \text { at1 }-\mathrm{A} 1 \times \text { at2 } / \operatorname{ad} 2 \times \text { ad1 }- \text { at1 } \\
\times \text { ad2 } \ldots \ldots(1) \\
\text { CTRAM = A1 } \times \text { ad2 }-A 2 \times \text { ad1 } / \text { ad2 } \times \text { at1 }- \\
\text { at1 } \times \text { ad2 } \ldots \ldots . .(2)
\end{gathered}
$$

Where ad1, ad2, at1, at2 are absorptivities of DEX and TRAM at 264 and $271 \mathrm{~nm}$ respectively. The absorbance of diluted mixed standards at 264 and $271 \mathrm{~nm}$ are denoted by A1 and A2. CDEX, CTRAM representsthe concentration of respective drugs.

The area under curve (Method B)

Additional other procedure designed for determination of two drugs in a blend using calculation of area under the curve of the spectra at a range of 259-266nm and 267$275 \mathrm{~nm}$. Two sets of equations designed by evaluating the absorptivity coefficient of both the drugs at each finalized wavelength scale.

$$
\begin{aligned}
& \text { AUC1 }=0.8971 \text { CDEX }+0.2429 \text { CTRAM } \ldots \ldots . . \\
& \text { III) }(\lambda 259-266 \mathrm{~nm}) \\
& \text { AUC2 = 4.341CDEX + 2.6238CTRAM ....... } \\
& \text { (IV) (ג267-275nm) }
\end{aligned}
$$

Where AUC1 and AUC2 are the area of under the curve of drug solutions when scanned at wavelength range $259-266 \mathrm{~nm}$ and $267-275 \mathrm{~nm}$ respectively. CDEX and CTRAM are concentrations ofDEXand TRAM respectively. The amount of each drugfrom admixture computed using mathematical expressions (III), (IV).

\section{Assay of dosage form Tablet}

Meticulously weighed powder of ten tablets equivalent to $400 \mathrm{mg}$ of DEX and $50 \mathrm{mg}$ TRAM was weighed. The weighed powder was solubilized in ethanol and volume was made up to $100 \mathrm{ml}$ using ethanol as a solvent. The drug solution was sonicated for $15-20$ mins 
and filtered through $0.45 \mu$ filter paper.Aliquots of drug solutions were diluted with ethanol to obtain $200 \mu \mathrm{g} / \mathrm{mL}$ and $25 \mu \mathrm{g} / \mathrm{mL}$ of DEX and TRAM respectively. Prepared sample solutions assessed by present proposed method.Results shown in table 3.

\section{Capsule}

Liquid from all ten capsules were emptied in a test tube. The volume of liquid equivalent to $400 \mathrm{mg}$ of DEX and $50 \mathrm{mg}$ of TRAM was solubilized in ethanol and volume was made up to $100 \mathrm{ml}$ using ethanol as a solvent. The drug solution was sonicated for $15-20$ mins and filtered through $0.45 \mu$ filter paper. Aliquots of drug solutions were diluted with ethanol to obtain $200 \mu \mathrm{g} / \mathrm{ml}$ and $25 \mu \mathrm{g} / \mathrm{ml}$ of DEX and TRAM respectively. Prepared sample solutions assessed by present proposed method.Results shown in table 3.

\section{RESULT AND DISCUSSION}

It is reported that synergism exists between Tramadol and Dexibuprofen but the simultaneous UV spectroscopic method for measurement of each drugfrom mixture doesn't exist.So,the above designed analytical procedures for determination of Dexibuprofen and Tramadol $\mathrm{HCl}$ in intermixed dosage form were found to be specific, peculiar,easy,reproducible, quick and profitable. The linearity range of the developed method was recorded in the concentration range $100-500 \mu \mathrm{g} / \mathrm{ml}$ and $20-120 \mu \mathrm{g} / \mathrm{ml}$ for Dexibuprofen and Tramadol $\mathrm{HCl}$. All statistical parameters of the developed method were validated according to $\mathrm{ICH}$ guidelines. The level of accuracy for the proposed method was estimated at 60,80 , and $100,120 \%$. The percentage of recovery for all developed methodsis between 99 to $100 \%$. Interdayand intraday variation for both the drugs was found to be at a minimum level. These methods can efficaciously pre-owned for determining Dexibuprofen and Tramadol $\mathrm{HCl}$ simultaneously in amalgamate bulk as well as the dosage form.

\section{CONCLUSION}

The proposed UV spectroscopic method is simple, precise, easy and also repeatable for evaluation of Dexibuprofen and Tramadol $\mathrm{HCl}$ simultaneously from the bulk and pharmaceutical dosage form.

\section{ACKNOWLEDGMENT}

I wish to acknowledge Dr. Gaurav Doshi and HemenS. Ved for their help and support in the compilation of the article.

Table 1: Statistical Parameter

\begin{tabular}{|c|c|c|}
\hline Parameter & DEX & TRAM \\
\hline Linearity range & $100 \mu \mathrm{g} / \mathrm{ml}-500 \mu \mathrm{g} / \mathrm{ml}$ & $20 \mu \mathrm{g} / \mathrm{ml}-120 \mu \mathrm{g} / \mathrm{ml}$ \\
\hline Slope value & 0.0088 & 0.00044 \\
\hline Intercept & 0.0013 & 0.0053 \\
\hline Correlation coefficient & 0.9983 & 0.9982 \\
\hline Limit of detection & $1 \mu \mathrm{g} / \mathrm{ml}$ & $0.5 \mu \mathrm{g} / \mathrm{ml}$ \\
\hline Limit of quantification & $10 \mu \mathrm{g} / \mathrm{ml}$ & $5 \mu \mathrm{g} / \mathrm{ml}$ \\
\hline InterdayPrecesion (\%RSD) & 0.31 & 0.0732 \\
\hline Intraday Precision(\%RSD) & 0.63 & 0.503 \\
\hline Robustess (\%RSD) & 0.402 & 0.25 \\
\hline
\end{tabular}

Table 2: Results dosage formulation

\begin{tabular}{|c|c|c|c|c|}
\hline Type of Method & Type Dosage form & $\mathrm{mg} /$ dosage form & $\begin{array}{c}\text { Obtained } \\
\text { /dosage form (mg) }\end{array}$ & Percentage recovery $\pm S D^{*}$ \\
\hline Method A & Tablet & $400 \mathrm{mg} 50 \mathrm{mg}$ & $399.3 \mathrm{mg} \quad 49.8 \mathrm{mg}$ & $99.82 \pm 0.43 \quad 99.6 \pm 0.21$ \\
\hline Method B & Tablet & $400 \mathrm{mg} 50 \mathrm{mg}$ & $399.7 \mathrm{mg} \quad 49.6 \mathrm{mg}$ & $99.92 \pm 0.2399 .2 \pm 0.11$ \\
\hline Method A & Liquid filled Capsule & $400 \mathrm{mg} 50 \mathrm{mg}$ & $400.01 \mathrm{mg} \mathrm{49.9mg}$ & $100.02 \pm 0.1299 .8 \pm 0.32$ \\
\hline Method B & Liquid filled Capsule & $400 \mathrm{mg} 50 \mathrm{mg}$ & $399.9 \mathrm{mg} \quad 49.9 \mathrm{mg}$ & $99.97 \pm 0.199 .8 \pm 0.33$ \\
\hline
\end{tabular}




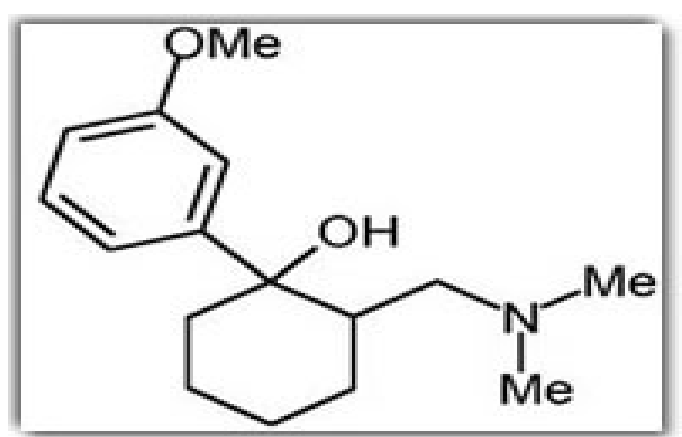

Fig. 1: Dexibuprofen

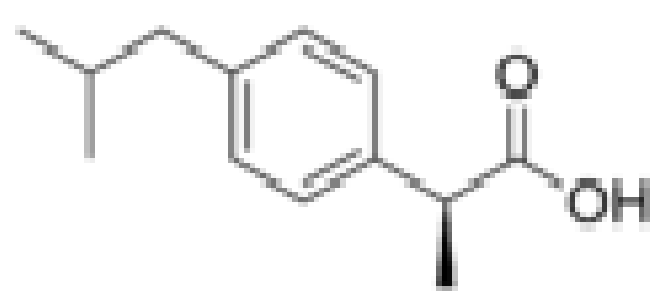

Fig. 2: Tramadol

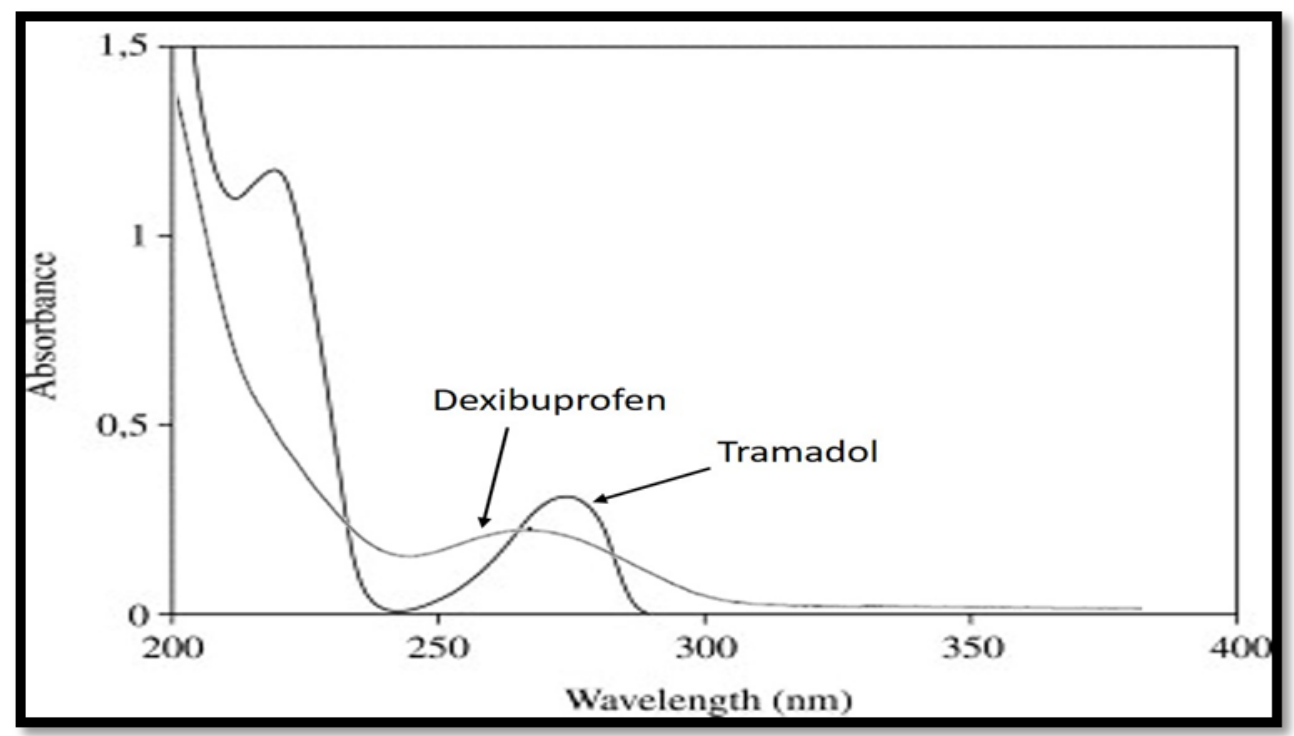

Fig. 3: Overlay spectra of Dexibuprofen and Tramadol $\mathrm{HCl}$ 


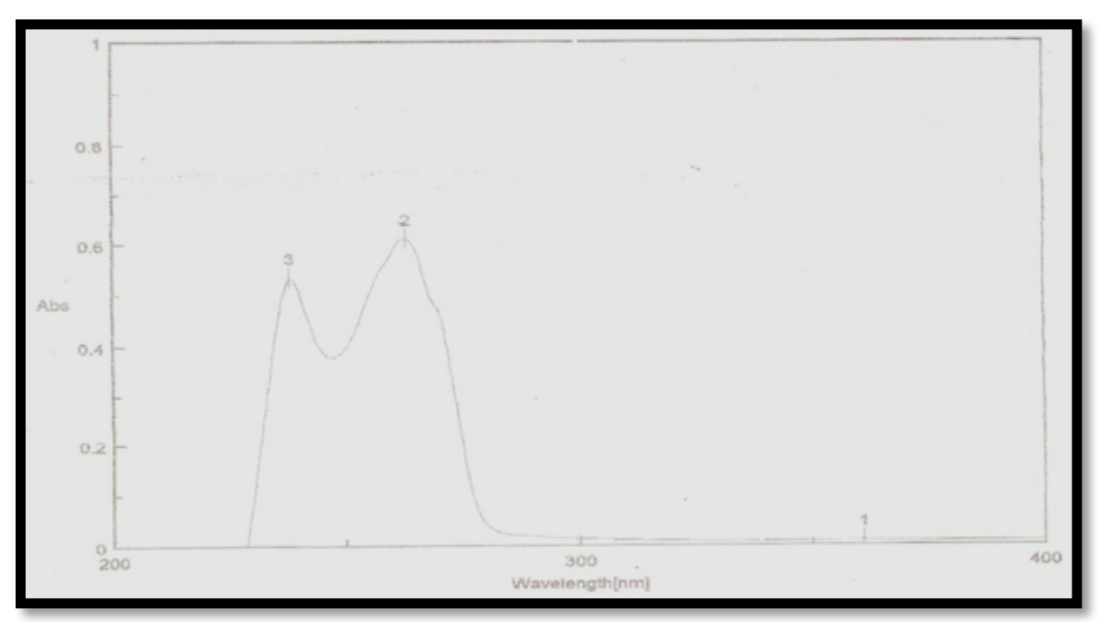

DEX

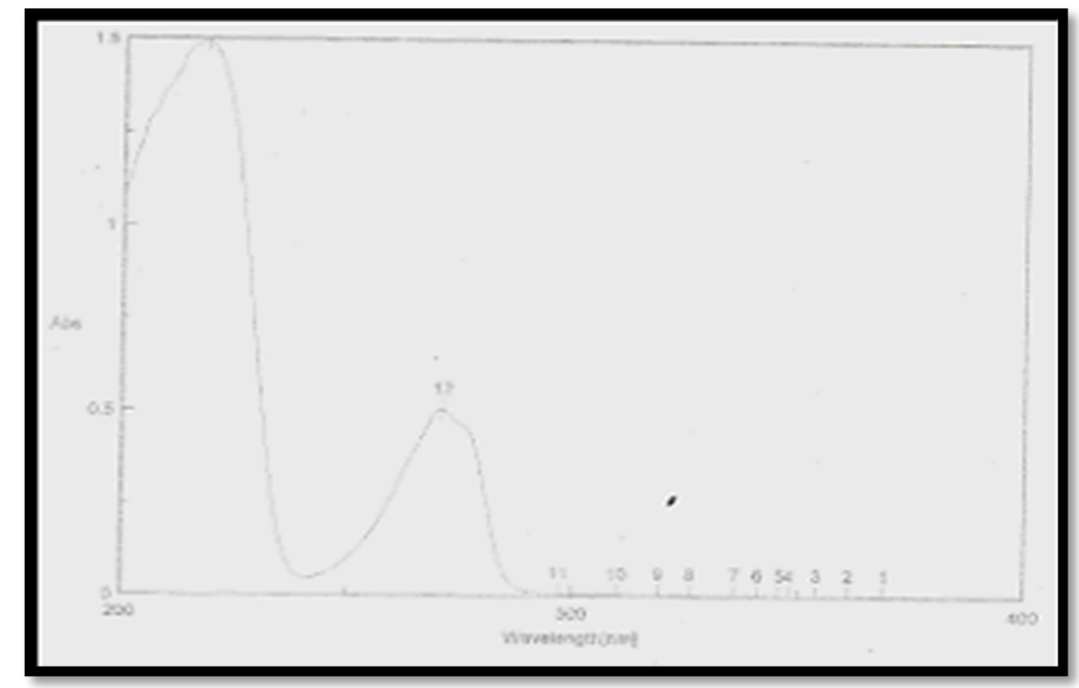

TRAM

Fig. 4: UV spectrum of Dexibuprofen and Tramadol

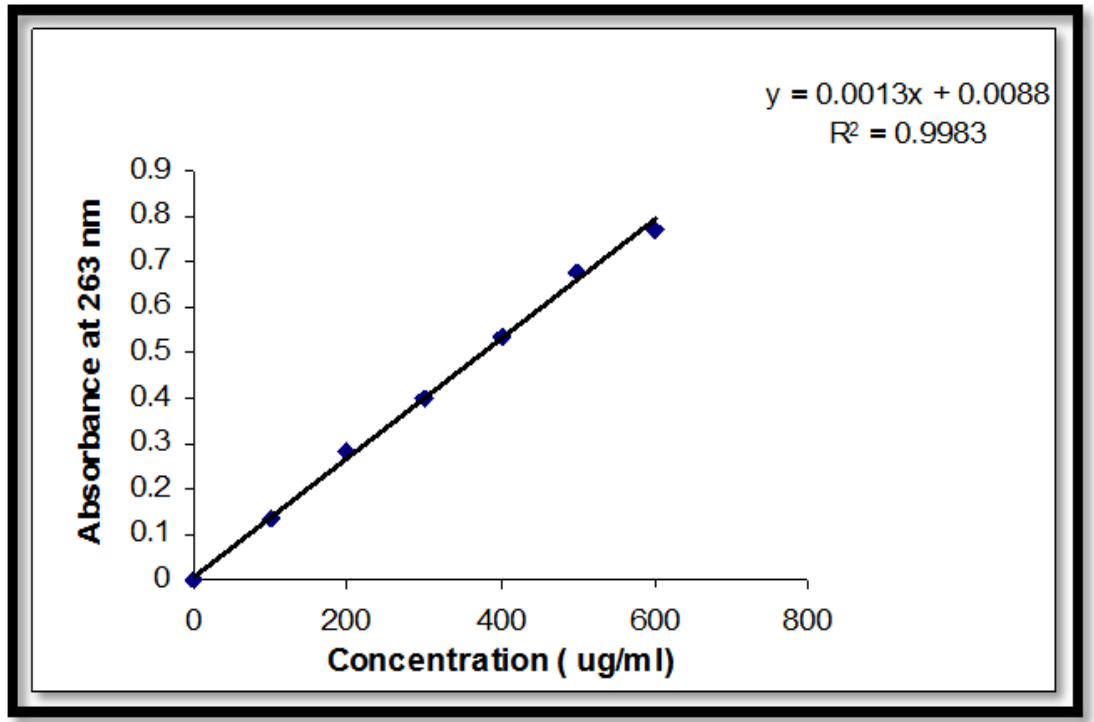

Fig. 5: Calibration curve of Dexibuprofen 


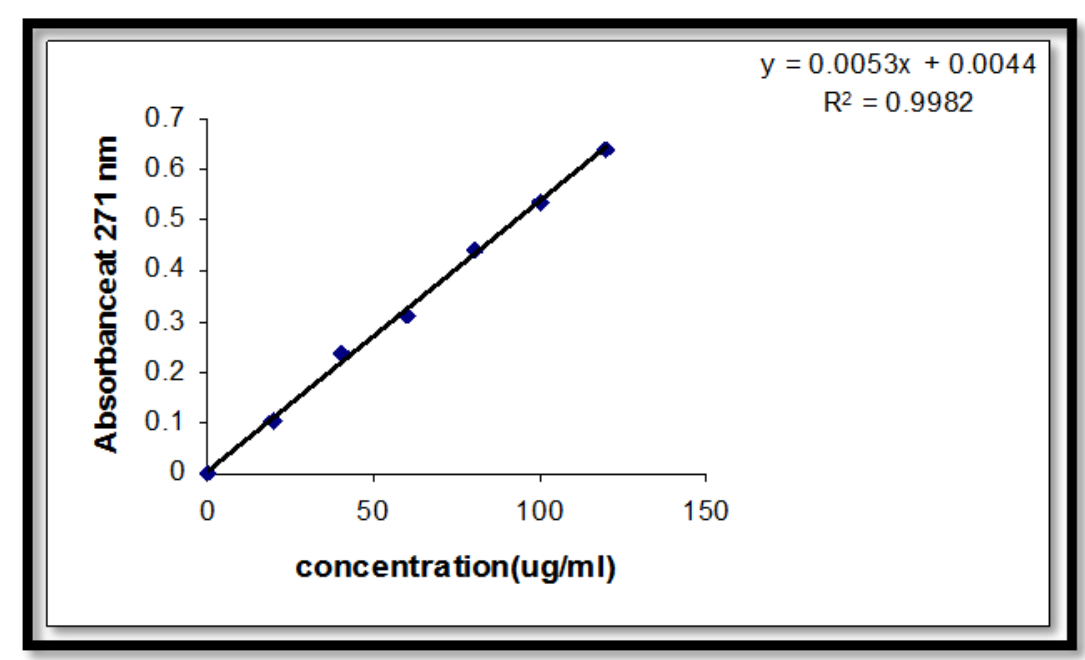

Fig. 6: Calibration curve of Tramadol $\mathrm{HCl}$

\section{REFERENCES}

1. Nikhade RV, Thakur AD, Choudhari SB and Chandewar AV. Simultaneous estimation of famotidine and ibuprofen by UV spectrophotometer using multicomponent mode method. J Pharm Res. 2011;4(7):2297-2299.

2. Clellan MC and Lesley J. Tramadol Paracetamoladis drug profile. Drugs. 2003;3(1):1079-10.

3. Nikhade RV, Thakur AD, Choudhari SB and Chandewar AV. Simultaneous estimation of famotidine and ibuprofen by UV spectrophotometer using multicomponent mode method. J Pharm Res. 2011;4(7):2297-2299.

4. Kumar S, Joshi A, Thakur R, Pathak AK and Shah K. Simultaneous estimation of Dexibuprofen and paracetamol by RP-HPLC method in combined dosage forms. Acta Pol Pharm. 2011;68(6):839-845.

5. Rachmale PM, Jadhav SB, Chaudhari $P D$, Surwase $B H$ and Palande AJ. Development and Validation of UVSpectrophotometric Methods for Simultaneous Determination of Ibuprofen and Tramadol in its Pure and Pharmaceutical Dosage Forms. International Journal of Pharmaceutical and Chemical sciences. 2013;2(2):656-663.
6. Gupta KR and Joshi RR. Simultaneous UV-Spectrophotometric determination of ibuprofen and paracetamol in pharmaceutical formulation. Pharm Sin. 2010;1(2):4451.

7. Goldring SR and Goldring MB. Clinical aspect, pathology and pathophysiology of osteoarthritis $\mathrm{J}$ musculoskelet Neuronal Interact. 2006;6:376-378.

8. Kothapalli LP, Karape AK, Thomas $A B$, Nanda RK, Gaidhani $P$ and Choudhari ME. Simultaneous spectrophotometric estimation of tramadol and paracetamol trometamol in pharmaceutical dosage form. Pharma Chem. 2011;3(1):365-371.

9. Florey K. Analytical profiles of drug substances and excipients. Vol. 11. New York: Academic Press. 1990;226

10. Shabir GA, Lough WJ and Arain SA. Evaluation and application of best practice in analytical method validation. J Liq Chrom Rel Tech. 2007;30:311- 333.

11. Walash M, Belal F, Eid M and Abass S. Simultaneous HPLC determination of tramadol and diclofenac sodium in their combined dosage forms. J Chromatogr Sci. 2011;49:159-164. 